\title{
Application of the L-M optimized algorithm to predicting blast vibration parameters
}

\author{
ZHANG Yi-feng ${ }^{1)}{ }^{4}$ (张艺峰) YAO Dao-ping ${ }^{1)}$ (姚道平) XIE Zhi-zhao ${ }^{1)}$ (谢志招) \\ YANG Jiang-feng ${ }^{2}$ (杨江峰) YE You-quan ${ }^{1)}$ (叶友权)
}

1) Xiamen Seismic Survey Research Center, Xiamen 361021, China

2) Institute of Geophysical Prospecting, SINOPEC Research Institute of Petroleum Exploration and Development, Nanjing 210014, China

Key words: blasting vibration; neural network; L-M algorithm; prediction CLC number: P315.9 Document code: A

Currently, the regression empirical formula with vibration peak as the safety index of single blasting vibration is widely applied in blasting engineering circles throughout the world. Due to complex blasting mechanism and blasting medium environment as well as plural influencing factors, it is difficult that all these factors can be taken into consideration by using one regression empirical formula. In addition, due to the inherent limitations of regression analysis (e.g., requiring good data distribution and large amount of samples), the vibration prediction by empirical formula is not ideal (LI, 1997; CHEN, 2001; ZHANG, 2001).

It is developing rapidly that multilayer feedforward network is used to solve the nonlinear separable problem due to the appearance of back-propagation algorithm (YAN and ZHANG, 2000), the multilayer feedforward network was also used for the prediction field of the blast seismic hazard in recent years, and good prediction results have been obtained ( YE et al, 2003; XIA et al, 2004; Singh and Singh, 2005; TANG et al, 2007). However, in all these studies, the peak of particle vibration was used as the unique output parameter of the network model, but the important role of blasting vibration frequency in the blast seismic hazard was neglected. Recent research by many scholars shows that the destruction of buildings not only depends on particle vibration intensity, but also is closely related to the vibration frequency (HU, 1999; TANG et al, 2001 ).

The neural network with improved BP algorithm (L-M algorithm) is used to establish the blasting vibration peak-dominant frequency prediction model. This method, which accords with the requirements of evaluation standard specified in "Rules of Explosion Safety" (Ministry of Labor and Ministry of Personnel of People's Republic of China, 2003) in which the peak is combined with dominant frequency, provides a feasible predicting idea for the implementation of safety criteria for blasting vibration in which the peak is combined with dominant frequency.

\section{BP neural network and L-M optimized algorithm}

\subsection{BP neural network}

Error back-propagation learning algorithm is used in the BP neural network. The essence of the BP neural network is to make the change of weights become smaller by gradient descent method and finally attains the minimal error. The BP neural network, which comprises several layers of neurons, can be divided into the input layer, hidden layer and output layer. Input information entering from the input layer is then transferred into the output layer after being treated by the hidden layer. The actual output of the output layer, which is inconsistent with the expected output, is transferred into back propagation, that is, output error is returned along the original

\footnotetext{
* Received 2008-02-02; accepted in revised form 2008-08-13.

^ Author for correspondence: zyf_xm@yahoo.com.cn
} 
pathway, and the weights $(\omega)$ of various layers of neurons are modified through learning to make the output error reach the expected target. The states of various layers of neurons can affect the states of the lower layer of neurons, and every neuron state corresponds to an activation function $(f)$ and a threshold value (b) (JIANG, 2001). We can see that the $I / O$ problem of a set of sample is changed into a nonlinear optimization problem by using the BP neural network. If this neural network is regarded as a mapping from input to output, this mapping is a multivariate highly nonlinear mapping, which is the theoretical basis for the neural network model when it is applied to the complicated evaluation of blasting vibration safety.

\subsection{The basic idea of L-M optimized algorithm}

The most fast grads descent methodology is adopted to modify the weight in the above BP algorithm; the training process gradually reaches the minimum point from one starting point along the inclined plane of error function in order to reduce the error to zero. The error curved surface, which is multi-dimensional space surface for the network in actual work, may tend to converge at local minimum point in the training process, the error can be increased by all multi direction changes from the point, thus the error curved surface can not escape from the local minimum point, which can lead to the network becoming non-convergent or can not reach global optimization (JIANG, 2001).

The Levenberg-Marquardt optimization algorithm is different, each iteration of the Levenberg-Marquardt optimization algorithm is not along a single negative gradient direction, the error is allowed to be searched along the direction of deterioration, network weight is adaptively adjusted between the most fast grads descent methodology and the Gauss-Newton method in order to make the network effectively converged, thus the convergence rate and the generalization ability of the network are greatly improved. The L-M optimization algorithm is also called as the damped least square method; the adjusting formula for weight is shown in equation (Lera and Pinzolas, 2002):

$$
\Delta \omega=\left(\boldsymbol{J}^{\mathrm{T}} \boldsymbol{J}+\mu L\right)^{-1} \boldsymbol{J}^{\mathrm{T}} \boldsymbol{e}
$$

Where $\boldsymbol{e}$ is error vector; $\boldsymbol{J}$ is the jacobian matrix of error versus weight differential; $\mu$ is a scalar. When $\mu$ increases, the algorithm is close to the steepest descent method with less learning rate, when $\mu$ decreases to zero, the algorithm is changed to smooth harmonic between the Gauss-Newton method, the algorithm

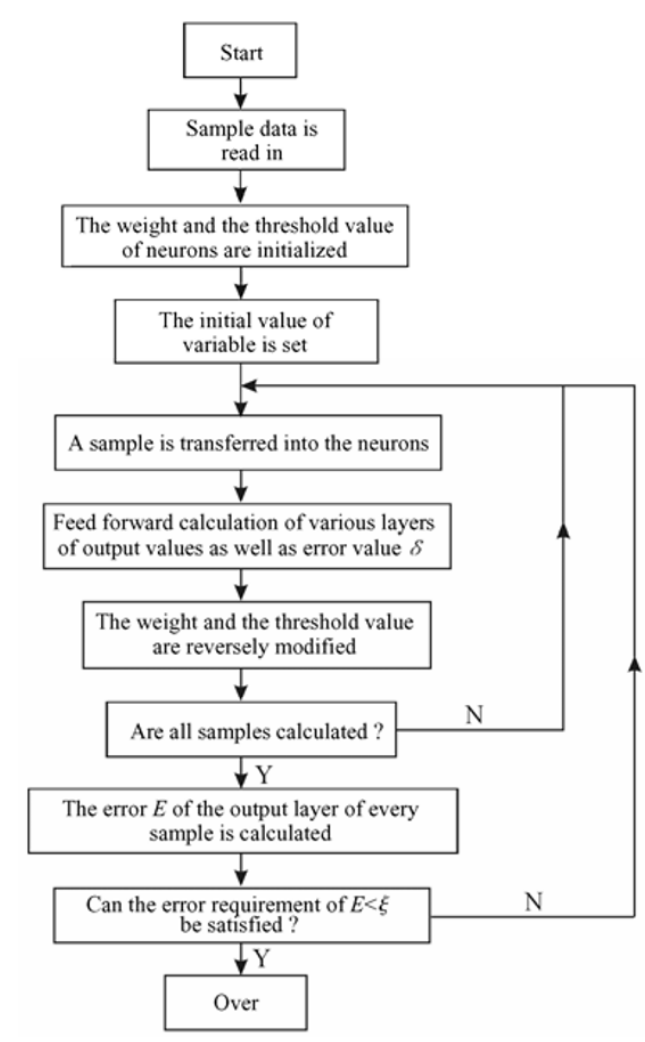

Figure 1 Algorithm flow chart flow is showed in the Figure 1.

\section{The establishment and trai ning of the network model}

There are plural factors that influence explosive vibration effect in rock mass, which can be summarized as four aspects: dynamic characteristics of the seismic source, site conditions in the blasting area, propagation space of the seismic wave as well as medium conditions and the dynamic response of the building (structure), their interaction determines the strength of explosive vibration effect in rock mass. In this paper, ten cases of blasting, which comprise seventy groups of data totally, are used to test the effect of blasting vibration on Liusheng tower, which is a state-level historical relic on Shugang Road, Shihu Port, Fujian Province, are taken as an example. A plurality of typical influencing factors are practically and comprehensively considered according to the project. Five characteristic features, comprising the total dose, the single-stage maximum loading, the number of sectional 
blasting, blast center distance and propagation media condition, are used as the main factors which affect vibration regularity. The application of the L-M optimization algorithm in the parameter prediction of blasting vibration is discussed. Table 1 shows the relative influencing factors and selective explanation of the blasting vibration, Table 2 shows the corresponding test data.

Table 1 The influence factor of blasting vibration

\begin{tabular}{|c|c|c|c|}
\hline $\begin{array}{l}\text { Serial } \\
\text { No. }\end{array}$ & $\begin{array}{l}\text { Classification of } \\
\text { effects }\end{array}$ & Influencing factors & Selective explanation \\
\hline \multirow[t]{9}{*}{1} & \multirow{9}{*}{$\begin{array}{l}\text { Dynamic character- } \\
\text { istics of seismic } \\
\text { source }\end{array}$} & Powder species & Rock emulsion explosive is used \\
\hline & & $\begin{array}{l}\text { The design of hole gird pa- } \\
\text { rameters }\end{array}$ & $\begin{array}{l}\text { New type of blasting technique of small array pitch and big pitch is } \\
\text { applied }\end{array}$ \\
\hline & & Ways of initiation & Millisecond subsection blasting and millisecond subsection fixation \\
\hline & & Pore size & Two pore sizes of $\varnothing 50$ 和 $\varnothing 105$ \\
\hline & & Number of hanging surfaces & One or two \\
\hline & & tamping length & $\begin{array}{l}\text { The change of hole depth is little, the range distances of holes are } \\
\text { basically identical, the change of tamping length is little }\end{array}$ \\
\hline & & Total dose & Be selected as the main factor \\
\hline & & Sectional dose & Be selected as the main factor \\
\hline & & $\begin{array}{l}\text { Millisecond delay interval } \\
\text { and sectional number }\end{array}$ & $\begin{array}{l}\text { Subordinates interval is uniform, sectional number is different, the } \\
\text { sectional number is selected as the main factor }\end{array}$ \\
\hline \multirow[t]{4}{*}{2} & \multirow[t]{4}{*}{$\begin{array}{l}\text { Site condition in } \\
\text { blasting area }\end{array}$} & Rock type & $\begin{array}{l}\text { The rock in this blasting area is Yanshanian medium-grained gran- } \\
\text { ite }(\gamma 5)\end{array}$ \\
\hline & & $\begin{array}{l}\text { Topography and geomor- } \\
\text { phology }\end{array}$ & $\begin{array}{l}\text { The landform belongs to III-grade corrosive and degraded terrace, } \\
\text { the change of topographic relief is little }\end{array}$ \\
\hline & & $\begin{array}{l}\text { Geological structure such as } \\
\text { fracture zone, fault, etc }\end{array}$ & $\begin{array}{l}\text { Three groups of joints, which are NE-trending, NW-trending and } \\
\text { north-east east trending, are developed, fault structure has not been } \\
\text { found }\end{array}$ \\
\hline & & $\begin{array}{l}\text { The thickness of casing soil } \\
\text { on the rod }\end{array}$ & $\begin{array}{l}\text { Casing soil in blasting area have been cleaned and the rock was } \\
\text { bare before blasting construction, }\end{array}$ \\
\hline \multirow[t]{3}{*}{3} & \multirow{3}{*}{$\begin{array}{l}\text { The space and dis- } \\
\text { tance of propagation, } \\
\text { propagation medium } \\
\text { conditions }\end{array}$} & $\begin{array}{l}\text { The plane distance between } \\
\text { the seismic source and the } \\
\text { test point }\end{array}$ & be selected as the main factor \\
\hline & & $\begin{array}{l}\text { The vertical height differ- } \\
\text { ence between the seismic } \\
\text { source and the test point }\end{array}$ & $\begin{array}{l}\text { The difference of the elevations between each test point and } \\
\text { blasting area is little }\end{array}$ \\
\hline & & $\begin{array}{l}\text { The condition of propaga- } \\
\text { tion medium }\end{array}$ & $\begin{array}{l}\text { The overburden thicknesses and the categories of the soil layer } \\
\text { where the test points between the blasting area and protected ob- } \\
\text { ject are located are different, the category is divided according to } \\
\text { 'Seismic Design Code', propagation medium conditions are proc- } \\
\text { essed numerically to be selected as the main factor. }\end{array}$ \\
\hline 4 & $\begin{array}{l}\text { Dynamic response of } \\
\text { protected object }\end{array}$ & $\begin{array}{l}\text { The predominant period of } \\
\text { structure self-vibration, } \\
\text { damping system }\end{array}$ & $\begin{array}{l}\text { The peak particle acceleration amplitude of blasting vibration is } \\
\text { little and the difference between the cycle and the natural vibration } \\
\text { period of Liusheng tower which is the projected object is larger, the } \\
\text { difference is not selected as the main influencing factor }\end{array}$ \\
\hline
\end{tabular}

Though it has physical meaning that the media condition of seismic wave propagation is used as the main influence factor, it is not a mathematical form and can not be directly used as the main factor to predict the input of the model. Currently, studies in which the media condition of propagation is processed numerically according to the propagation law of blasting seismic wave, are not too many by now. The seven test points of each blasting are described numerically referring to the regulations of the characteristic parameters of site condition showed as Table 4.1.3 regulated in the "Seismic Design Code" (Ministry of Construction of People's Republic of China, 2001), the 
results are shown as Table 3.

Table 2 The related parameter statistics of blasting

\begin{tabular}{ccccc}
\hline $\begin{array}{c}\text { Trial blasting } \\
\text { No. }\end{array}$ & $\begin{array}{c}\text { Blasting total } \\
\text { dose/kg }\end{array}$ & $\begin{array}{c}\text { The maximum single stage } \\
\text { dose } / \mathrm{kg}\end{array}$ & Blasting sectional number & Blast center distance/m \\
\hline 1 & 36.3 & 12.9 & 4 & $69.5 \sim 183.5$ \\
2 & 37.3 & 13.5 & 3 & $25.7 \sim 161.2$ \\
3 & 49.6 & 18.0 & 3 & $27.7 \sim 247.6$ \\
4 & 27.3 & 17.5 & 2 & $80.0 \sim 219.5$ \\
5 & 44.7 & 24.2 & 2 & $50.1 \sim 242.4$ \\
6 & 216.0 & 96.0 & 3 & $44.6 \sim 281.6$ \\
7 & 134.0 & 54.0 & 3 & $33.2 \sim 246.0$ \\
8 & 157.0 & 78.5 & 2 & $35.4 \sim 256.5$ \\
1 & 189.0 & 68.0 & 4 & $56.0 \sim 275.4$ \\
\hline
\end{tabular}

Table 3 Numeric expression of seismic wave propagation medium conditions

\begin{tabular}{cccccccc}
\hline Test point & 1 & 2 & 3 & 4 & 5 & 6 & 7 \\
\hline Type of soil & Rock & $\begin{array}{c}\text { Medium-hard } \\
\text { soil }\end{array}$ & $\begin{array}{c}\text { Medium-soft } \\
\text { soil }\end{array}$ & $\begin{array}{c}\text { Medium-hard } \\
\text { soil }\end{array}$ & $\begin{array}{c}\text { Soft } \\
\text { soil }\end{array}$ & $\begin{array}{c}\text { Medium-soft } \\
\text { soil }\end{array}$ & $\begin{array}{c}\text { Soft } \\
\text { soil }\end{array}$ \\
\hline $\begin{array}{c}\text { Digitalization of } \\
\text { test point }\end{array}$ & 1 & 2 & 3 & 2 & 4 & 3 & 4 \\
\hline
\end{tabular}

As above-mentioned, the five characteristic variables, comprising the total dose, the single-stage maximum loading, the number of sectional blasting, blast center distance and propagation media condition, are used as the five neurons of the input layer of the network, and the blasting vibration peak and the dominant frequency are used as the neurons of the output layer. The identification of the node number of the hidden layer (interlayer) is a very important part for neural network design. Up to now, there is not any accurate or scientific analytical expression to determine the number of the hidden layer (YAN, 2000; JIANG, 2001).

The optimization stages of the number of hidden nodes used by the author are as follows.

1) The purpose range of the node number in the hidden layer is determined according to kolmogorov theory (Feisi Technological Products Research and Development Center, 2005) in order to determine the initial number of hidden nodes;

2) The sample set selected is used for training network, and then an output error $\Delta y$ is gotten;

3) $k$ nodes of hidden layer are added, the network with $n '=n+k$ nodes of hidden layer is retrained, then a new output error $\Delta y$ is obtained;

4) The cycle of the following process is repeated until that the characteristics of the network no longer increase:

(1) $\Delta y$ and $\Delta y^{\prime}$ are compared;

a. if $\Delta y^{\prime}>\Delta y, k^{\prime}\left(k^{\prime}<k\right)$ nodes of hidden layer are reduced, $n^{\prime}=n+k-k^{\prime}$;

b. if $\Delta y^{\prime} \leq \Delta y, k^{\prime}\left(k^{\prime}<k\right)$ nodes of hidden layer are added continuously, $n^{\prime}=n+k+k^{\prime}$;

(2) The original $\Delta y^{\prime}$ is used as the new $\Delta y$, and the original $k^{\prime}$ is used as the new $k$, that is $\Delta y=\Delta y^{\prime} ; k=k^{\prime}$;

(3) The network with the the number of hidden nodes changed is retrained, then a new output error is obtained to be used as the new $\Delta y$ '.

The number of hidden nodes is determined as 17 through tests, thus the structure of neural network model of the $\mathrm{L}-\mathrm{M}$ algorithm is determined as $5-17-2$.

The first nine blasting of test data are used as the training set in this network model, network sample is trained by using the L-M optimization algorithm. From the first group of data, the network is trained to study the first group of sample, the training result are used for the input of the second group of sample and variables is inputted to predict the output of the second group; then the network is trained to study the second group of sample to predict the third group of sample, and so on. The network training is terminated until that the ninth group of data are inputted. Normalization processing is made for all these data before training. 


\section{Analysis of prediction results}

The trained neural network model above was employed in the prediction of testing data for the tenth blasting, meanwhile San's peak empirical formula (National Standards of People's Republic of China, 2003) and TANG's frequency empirical formula (TANG et al, 2001) were employed in the regression analysis of vibration peak and dominant frequency for data samples. (In San's formula, coefficient $k=110.54$ and $\alpha=1.92$; in TANG's formula, coefficient $k=17.5$ ), then the data of the tenth blasting was predicted.

Comparison between measured results and two kinds of predicting results for the blasting is shown in Table 4 and Figure 2. As shown in the paper, the neural network based on L-M algorithm is provided with its advantage: Predicted relative error of blasting vibration peak and dominant frequency in this model is $10.39 \%, 10.83 \%$ respectively while predicted relative error of blasting vibration peak and dominant frequency by regression empirical formula is $26.18 \%, 11.16 \%$ separately. These results show that the error of the neural network model based on L-M algorithm is smaller than that of the regression prediction formula. As shown in the figure, the curve shape of predicted data is very consistent with that of measured data. With the increase of trained data of neural network, the network will get closer to measured results gradually. The error change of the regression prediction is provided with a fluctuate tendency and is not convergent.

Table 4 Comparison between measured results and two kinds of predicting results

\begin{tabular}{|c|c|c|c|c|c|c|c|c|c|}
\hline \multicolumn{5}{|c|}{ Prediction of peak velocity } & \multicolumn{5}{|c|}{ Prediction of dominant frequency of vibration } \\
\hline $\begin{array}{l}\text { Measured } \\
\text { results } \\
/ \mathrm{cm} \cdot \mathrm{s}^{-1}\end{array}$ & $\begin{array}{c}\text { Neural network } \\
\text { L-M algorithm } \\
\qquad / \mathrm{cm} \cdot \mathrm{s}^{-1}\end{array}$ & $\begin{array}{c}\text { Relative } \\
\text { error }\end{array}$ & $\begin{array}{l}\text { San's } \\
\text { formula } \\
/ \mathrm{cm} \cdot \mathrm{s}^{-1}\end{array}$ & $\begin{array}{l}\text { Relative } \\
\text { error }\end{array}$ & $\begin{array}{l}\text { Measured } \\
\text { results } \\
/ \mathrm{Hz}\end{array}$ & $\begin{array}{c}\text { Neural network } \\
\text { L-M algorithm } \\
\text { /Hz }\end{array}$ & $\begin{array}{c}\text { Relative } \\
\text { error }\end{array}$ & $\begin{array}{l}\text { TANG's for- } \\
\text { mula/Hz }\end{array}$ & $\begin{array}{c}\text { Relative } \\
\text { Error }\end{array}$ \\
\hline 0.6279 & 0.6860 & $9.25 \%$ & 0.5208 & $17.06 \%$ & 17.11 & 14.835 & $13.30 \%$ & 15.5845 & $8.92 \%$ \\
\hline 0.4132 & 0.4450 & $7.70 \%$ & 0.2819 & $31.784 \%$ & 16.15 & 14.450 & $10.53 \%$ & 14.4524 & $10.51 \%$ \\
\hline 0.3259 & 0.2900 & $11.02 \%$ & 0.2059 & $36.8 \%$ & 16.11 & 14.740 & $8.50 \%$ & 13.9339 & $13.51 \%$ \\
\hline 0.1180 & 0.1383 & $17.20 \%$ & 0.1176 & $0.37 \%$ & 16.46 & 18.843 & $14.48 \%$ & 13.0972 & $20.43 \%$ \\
\hline 0.0749 & 0.0796 & $6.28 \%$ & 0.0538 & $28.14 \%$ & 13.04 & 12.088 & $7.30 \%$ & 12.0837 & $7.33 \%$ \\
\hline 0.0477 & 0.0423 & $11.32 \%$ & 0.0318 & $33.28 \%$ & 12.98 & 14.012 & $7.95 \%$ & 11.4872 & $11.5 \%$ \\
\hline 0.0412 & 0.0371 & $9.95 \%$ & 0.0264 & $35.85 \%$ & 12.00 & 13.653 & $13.78 \%$ & 11.2869 & $5.94 \%$ \\
\hline $\begin{array}{c}\text { Average } \\
\text { error }\end{array}$ & & $10.39 \%$ & & $26.18 \%$ & $\begin{array}{c}\text { Average } \\
\text { error }\end{array}$ & & $10.83 \%$ & & $11.16 \%$ \\
\hline
\end{tabular}
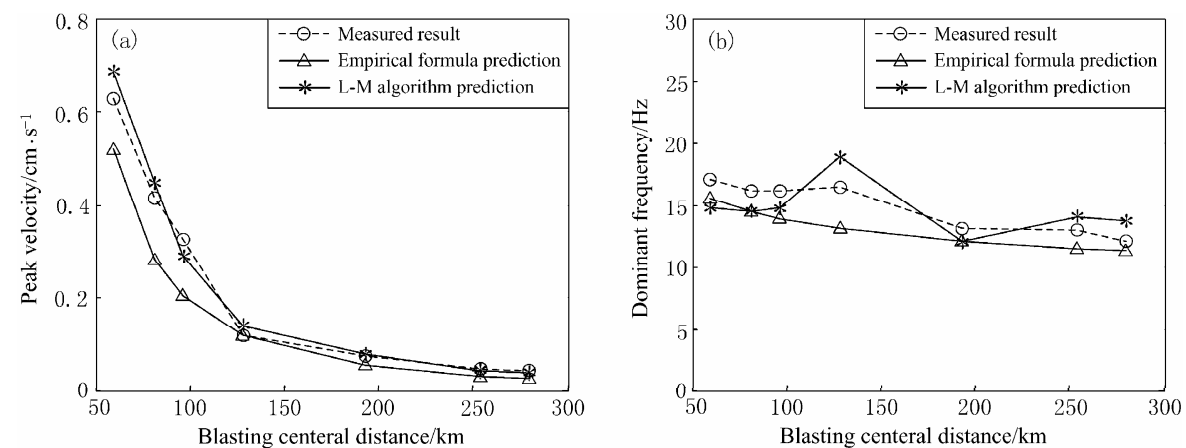

Figure 2 Comparison between measured results and two kinds of predicting results

\section{Conclusions}

The engineering example showed that the application of neural network model based on L-M algorithm in the prediction of blast vibration parameters is feasible. The L-M algorithm had improved the disadvantage of BP algorithm. Compared with empirical formulae, the neural network method overcomes the problem and disadvantages of the application of conventional regression analysis methods and is provided with certain practical signifi- 
cance in the development of blast vibration testing method:

1) Explosion mechanism and media environment of blasting are extreme complicate, factors which affect blast vibration also have characteristic of complexity and polytropy. Several main factors which affect blast vibration can be selected as input layers in the application of neural network based on L-M algorithm, so the predictive accuracy can be improved.

2) Compared with single vibration peak prediction formula, blasting vibration peak and dominant frequency were used as evaluation indexes in neural network model, and it was in accord with the evaluation standard of vibration safety with vibration peak combined with dominant frequency in 'Blasting Safety Regulations' and was provided with a feasible prediction idea for the actual implementation of vibration safety standard of the evaluation of peak and dominant frequency.

Although the effect of transmit medium on blasting vibration has been considered in the neural model, the numerical description of the condition of transmit medium was imprecise which affected the prediction of the model to some extent. The solution of this problem will be further studied and revised by the author.

\section{References}

CHEN Shou-ru. 2001. Comparison and selection of two kinds of prediction formulas for particle vibration velocity [C]//Proceedings of the Seventh Chinese Symposium on Engineering Blasting. Chengdu: the Seventh Chinese Symposium on Engineering Blasting: 702-706 (in Chinese).

Feisi Technological Products Research and Development Center. 2005. Artificial Neural Theory and Realization on MATLAB7.0 [M]. Beijing: Publishing House of Electronics Industry: 260-261 (in Chinese).

HU Zong-wu. 1999. Basis of Engineering Vibration Analysis [M]. Shanghai: Shanghai Jiao Tong University Press: 113-120 (in Chinese). JIANG Zong-li. 2001. Introduction to Artificial Neural Network [M]. Beijing: Higher Educational Press: 40-53 (in Chinese).

Lera G and Pinzolas M. 2002. Neighhorhood based Levenberg-Marquardt algorithm for neural network training [J]. IEEE Transactions on Neural Networks, 13(5): 1 200-1203.

LI Bao-zhen. 1997. Discussion of the relation of elevation difference, blast vibration intensity and attenuation rule [C]//Proceedings of the Sixth Chinese Symposium on Engineering Blasting. Shenzhen: the Sixth Chinese Symposium on Engineering Blasting: $778-783$ (in Chinese).

Ministry of construction of People's Republic of China. 2001. Code for Seismic Design of Buildings (GB6722-2003) [S]. Beijing: China Architecture and Building Press: 21-23 (in Chinese).

Ministry of Labor and Ministry of Personnel of People's Republic of China. 2003. Blasting Safety Regulations (GB50011-2001) [S]. Beijing: China Standard Press: 42-43 (in Chinese).

Singh T N and Singh V. 2005. An intelligent approach to prediction and control ground vibration in mines [J]. Geotechnical and Geological Engineering, 23(3): 249-262.

TANG Chun-hai, YU Ya-lun, WANG Jian-zhou. 2001. Elementary study of safety criterion for blasting vibration [J]. Nonferrous Metals, 53(1): 1-3 (in Chinese).

TANG Hai, SHI Yong-qiang, LI Hai-bo, et al. 2007. Prediction of peak velocity of blasting vibration based on Neural Network [J]. Chinese Journal of Rock Mechanics and Engineering, 26(Z1): 3533-3 539 (in Chinese).

XIA Meng-hui, DONG Xiang-shan, ZHANG Wei-min, et al. 2004. Application research of neural network model for forecasting the intension of blasting vibration [J]. Nonferrous Metals (Mining), 56(3): 25-27 (in Chinese).

YAN Ping-fan and ZHANG Chang-shui. 2000. Artificial Neural Network and Simulation Evolutionary Computation [M]. Beijing: Tsinghua University Press: 17-23 (in Chinese).

YE Zhou-yuan, MA Jian-jun, CAI Lu-jun, et al. 2003. An optimized calculation of particle vibration velocity by means of the vibration data form blasting monitoring [J]. Mining Research and Development, 23(4): 48-51 (in Chinese).

ZHANG Ji-chun. 2001. Vibration characteristics of blasting in bed rock mass at Sanxia project [J]. Explosion and Shock Waves, 21(2): 131-137 (in Chinese). 